\title{
Discrimination of a wet snow cover using passive microwave satellite data
}

\author{
A. E. Walker and B. E. Goodison \\ Canadian Climate Centre, 4905 Dufferin Street, Downsview, Ontario, Canada M3H 5T4
}

\begin{abstract}
Snow-cover monitoring using passive microwave remote sensing methods has been shown to be seriously limited under melt conditions when the snowpack becomes wet. A wet snow indicator has been developed using DMSP $\mathrm{SSM} / \mathrm{I} 37 \mathrm{GHz}$ dual-polarization data for the open prairie region of western Canada. The indicator is used to identify areas of wet snow and discriminate them from areas of snow-free land. Validation and testing efforts have illustrated that the addition of the indicator to the current SSM/I snow water equivalent algorithm provides a more accurate representation of spatial snow coverage throughout the winter season for the open prairie region. The improved spatial and temporal information resulting from the use of the indicator enhances both climatological and hydrological analyses of snow-cover conditions using passive microwave data. Although the wet snow indicator has only been validated for the open prairie region of western Canada, it may also be applicable to other regions of similar terrain and vegetative characteristics. However, in areas of dense vegetation, such as the boreal forest, the performance of the indicator is poor due to the generally low $37 \mathrm{GHz}$ polarization differences of the vegetation cover.
\end{abstract}

\section{INTRODUCTION}

The use of passive microwave satellite data to derive snow-cover parameters on a global, national and regional basis has been actively developed and tested by several research groups (Chang and others, 1987; Goodison, 1989; Hallikainen and Jolma, 1986; Kunzi and others, 1982). Although the results have been very encouraging for dry snow conditions, the presence of liquid water within the snowpack severely limits the quantitative determination of snow-cover parameters. In most cases, it has not been possible to discriminate between wet (melting) snow areas and snow-free land (Kunzi and others, 1982). This problem has limited the effective use of passive microwave snow-cover products for providing real-time information and as a basis for climate timeseries analysis.

In Canada, algorithms have been developed and have undergone continuing validation for the determination of snow water equivalent (SWE) from passive microwave data for the Canadian Prairie region (Goodison, 1989). The launch of the Special Sensor Microwave Imager $(\mathrm{SSM} / \mathrm{I})$ on the U.S. Defense Meteorological Satellite Program (DMSP) F-8 satellite in June 1987, presented the capability to monitor snow conditions on a daily basis over the Canadian Prairies throughout the winter season. Since the 1988-89 winter season, SWE maps have been derived from near real-time SSM/I data and distributed by facsimile machine weekly to federal and provincial water resources agencies who use the information to monitor snow conditions, plan for ground surveys, and prepare runoff forecasts. Thirkettle and others (1991) described this program.

With users relying on the SWE map product to make operational decisions, it became imperative that the information should be as accurate and reliable as possible. During recent years, periods with temperatures near and above $0^{\circ} \mathrm{C}$ have become more common during the winter months in the Canadian prairie region, resulting in more frequent melting snow conditions over extensive areas. In an effort to overcome the limitation of the SSM/I SWE algorithms under these conditions, a wet snow indicator was developed to discriminate between areas of wet (melting) snow and actual snow-free land. Validation and testing of the indicator has been on-going with the near real-time SSM/I SWE map product since the 1990-91 winter season. This paper describes the derivation of this empirical wet snow indicator and provides examples where it has been successfully implemented over the Canadian prairie study area using $\mathrm{SSM} / \mathrm{I}$ data.

\section{EFFECT OF WET SNOW ON SSM/I DERIVED SNOW WATER EQUIVALENT}

Goodison (1989) provides a general discussion on the development and testing of algorithms for monitoring areal snow water equivalent over the Canadian prairies using SSM/I data. The current operational SWE algorithm uses the vertically polarized brightness temperature gradient between 37 and $19 \mathrm{GHz}$. Overall, the 
algorithm provides reliable SWE retrievals for open areas for dry snow conditions, with values generally within 10$20 \mathrm{~mm}$ of averaged ground-based survey measurements.

The presence of liquid water within the snowpack alters the microwave emission characteristics such that internal absorption of the microwave radiation increases significantly and volume scattering decreases (Foster and others, 1984). Experimental studies, which have been conducted using ground-based microwave radiometers, have provided important background information on the microwave signatures of wet snow. Matzler (1987) discusses the microwave response to wet snow and provides a summary of microwave signatures which have resulted from ground-based studies. Under wet snow conditions, the typical passive microwave response is an increase in the observed brightness temperatures and a black-body behavior at vertical polarization. Therefore, the 37 and $19 \mathrm{GHz}$ vertical polarization brightness temperature gradient becomes very small (near zero) and upon application of the SSM/I SWE algorithm, the values produced are "zeros", which erroneously indicate an absence of snow.

Goodison and others (1990) illustrated that during periods of winter melt, dramatic changes in SSM/I-

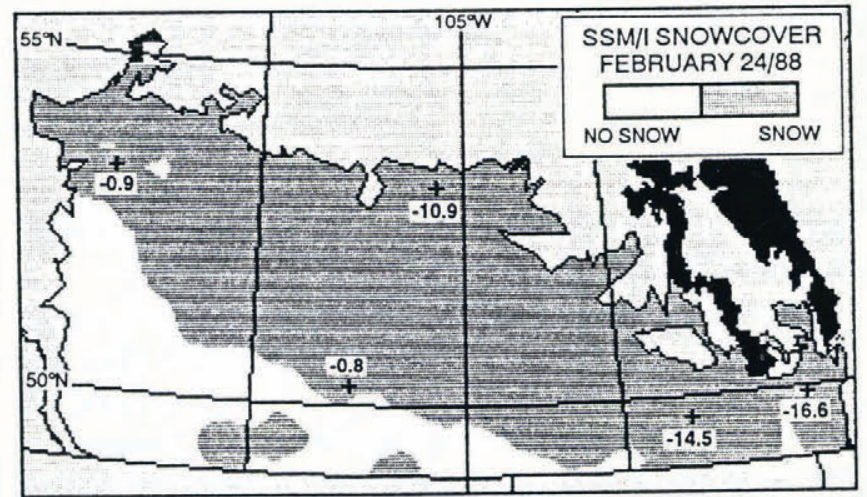

a

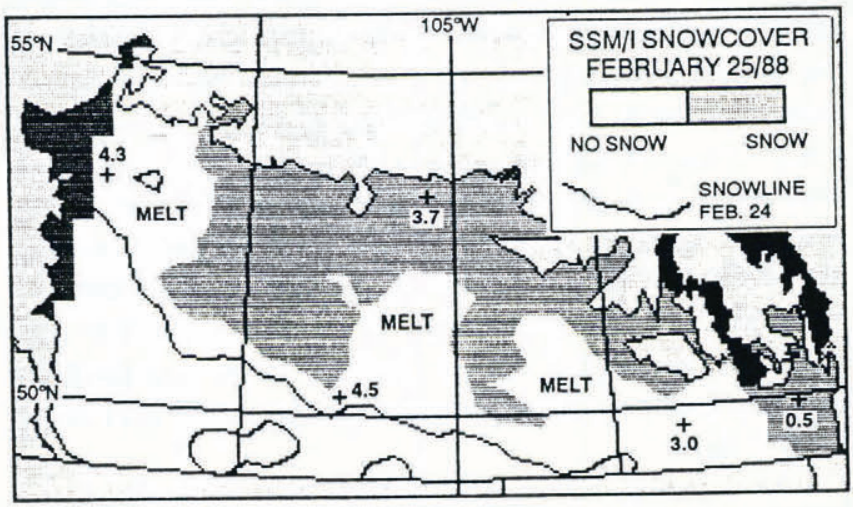

b

Fig. 1. Canadian prairies snow cover derived using the SSM|I SWE algorithm for (a) 24 February 1988 (2000 h CST). (b) for 25 February 1988 (2000 h CST). Air temperatures at synoptic stations at the time of the SSM/I orbit are plotted. The snow boundary extracted from Fig. 1(a) defines the area where the snow has "disappeared" due to possible wet snow conditions. derived SWE can take place within a 48-hour period due to changes in weather; within affected regions the snow cover may "disappear" and "reappear" on successive orbit passes. The rapid and dynamic response of SWE retrievals to even very short mild periods emphasizes the need to be able to identify and discriminate wet snow areas if accurate maps of SWE are to be produced for both real-time operational use and time series analysis. It must be realized that "wet snow" in the context of passive microwave radiometry does not necessarily mean a ripe snowpack in the hydrological sense; even a small amount of liquid water on the snow surface will adversely affect SWE retrievals.

Figure 1 illustrates the effect of a winter melt event on the SSM/I-derived snow cover. Figure la depicts the areal snow coverage over the Canadian prairies as derived using the SWE algorithm for a SSM/I orbit on 24 February 1988 at 2000 h CST (25 February 0200 h GMT). The temperature recorded at selected meteorological stations at the time of the satellite overpass is also plotted; for most stations the temperatures are well below zero, precluding melt. Figure $1 \mathrm{~b}$ displays the areal snow coverage derived from a SSM/I orbit 24 hours later on 25 February. Areas of apparent melt can be identified when one compares the snow extent to that of the previous day. Air temperatures above $0^{\circ} \mathrm{C}$ at the time of the satellite overpass in the regions where the snow has "disappeared" confirm the probability of wet snow conditions due to melting. Ground snow survey observations taken in southern Saskatchewan during the daytime on 25 February 1988 as part of this Prairie validation research, provided further confirmation of the existence and extent of melting snow (Goodison, 1989).

\section{DERIVATION OF A WET SNOW INDICATOR}

With passive microwave remote sensing methods, one means of identifying the onset and cessation of melt, even the short melt periods, during the winter season is by monitoring the snow conditions on a daily basis or by viewing successive orbits (to detect daytime melt and nighttime refreeze). Currently, this is best done by acquiring passive microwave data in swath format in near real-time. If the snowcover is only monitored on selected days during the winter or by using archived historical data which may have been gridded or binned there is the possibility of deriving an erroneous interpretation of the snow conditions, as wet snow areas may be interpreted as snow-free land.

To provide a more accurate representation of snow cover conditions, it is necessary to identify areas of wet (melting) snow, preferably using microwave brightness temperatures alone to discriminate these areas from actual snow-free land. To isolate a passive microwave signature for wet snow, data sets corresponding to known winter melt events were extracted from archived SSM/I data acquired in near real-time during the winter seasons since 1987-88. In each case, orbits were selected for premelt, melt and post-melt conditions, which generally spanned a two-to-three day time period. The SWE algorithm was applied to swath data for each selected orbit overpass and the retrievals were displayed on a PC- 


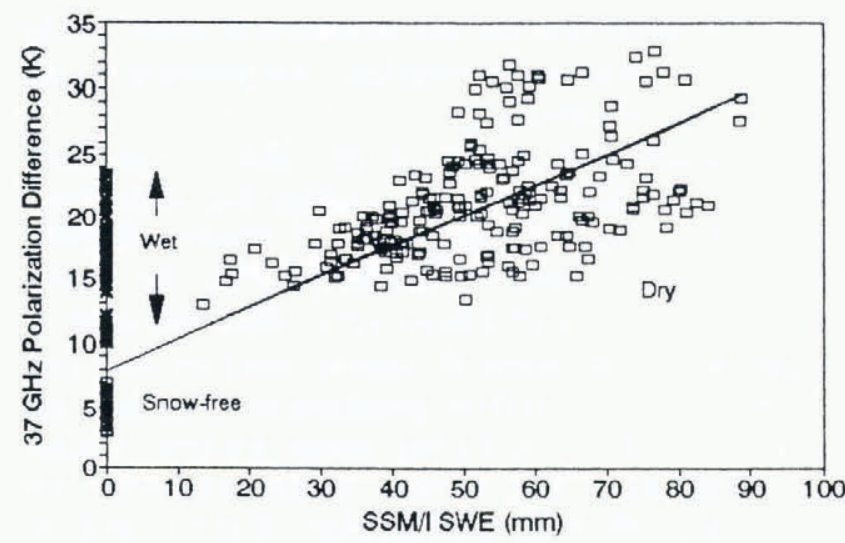

Fig. 2. SSM/I $37 \mathrm{GHz}$ polarization differences corresponding to wet snow, dry snow and snow-free land from a Canadian prairies melt event in February 1989.

based image display system. Areas which exhibited a decrease in SWE to zero on successive orbits were identified as wet snow (melt) regions. Brightness temperatures ( $\mathrm{T}_{\mathrm{B}}$ values) for the 19 and $37 \mathrm{GHz} \mathrm{SSM} / \mathrm{I}$ channels (horizontal and vertical polarization) were extracted for these regions for the pre-melt (dry snow) and melt (wet snow) conditions. $T_{B}$ values for known snow-free areas were also extracted for the analysis.

For each set of $T_{B}$ values extracted, the polarization differences (vertical minus horizontal) for the 19 and $37 \mathrm{GHz}$ channels and the difference between the 19 and $37 \mathrm{GHz}$ vertical channels were analyzed. Analysis of the three snow conditions (dry, wet and snow-free) revealed that the $37 \mathrm{GHz}$ polarization difference exhibited a clear discrimination between wet snow and snow-free land. Typical polarization differences for snow-free open prairie areas ranged from 3 to $11 \mathrm{~K}$, while those for wet snow areas were generally much higher, ranging from 9 to $24 \mathrm{~K}$. The polarization differences for dry snow areas were similar to that of wet snow, ranging from 8 to $33 \mathrm{~K}$.

Figure 2 exhibits the $37 \mathrm{GHz}$ polarization differences for dry snow, wet snow and snow-free land corresponding to a melt event on 24 February 1989. Although both wet snow and snow-free land result in zero SWE values using

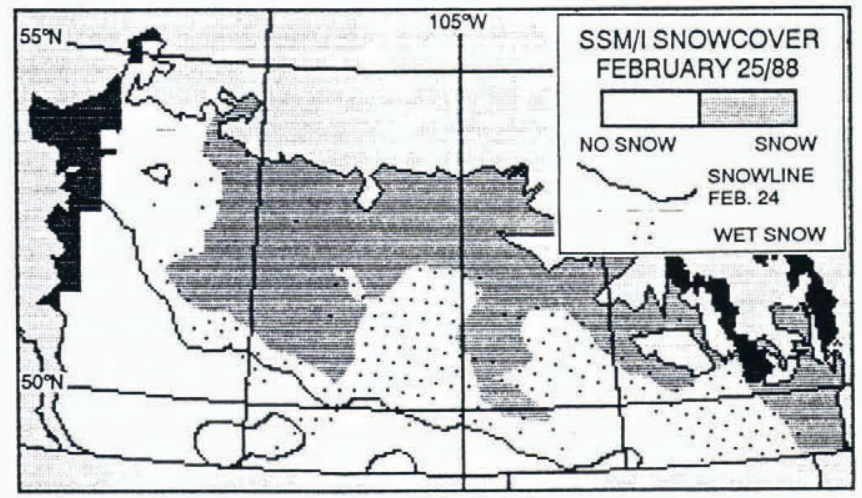

Fig. 3. Wet snow areas defined using the SSM/I wet snow indicator for 25 February 1988 (2000 h CST). the SSM/I algorithm, their associated $37 \mathrm{GHz}$ polarization differences appear distinct on the graph. The polarization differences for dry snow conditions are also distinct from snow-free land; the largest differences are associated with high SWE values.

A total of five melt events were examined in the manner described above and the results in each case were similar to that displayed in Figure 2. Based on these results, a polarization difference of $10 \mathrm{~K}$ was defined as the threshold to discriminate between wet snow and snow-free land. When SWE values are zero, a polarization difference of $10 \mathrm{~K}$ or greater implies wet snow, while a difference of less than $10 \mathrm{~K}$ indicates snow-free ground. This wet snow indicator has been assimilated into the current SSM/I SWE algorithm and is automatically applied if a SWE value of zero is derived at a pixel location. On the operational SWE map product, a location which has been classified as wet snow is flagged with a special symbol.

Figure 3 illustrates the application of the wet snow indicator to the same 25 February $1988 \mathrm{SSM} / \mathrm{I}$ orbit as displayed in Figure 1b. As expected, the indicator appears in the regions which were defined as melting snow in Figure $1 \mathrm{~b}$; within the snow-free zone the indicator is absent. There are, however, two "melt" regions where the indicator is noticeably absent; the corresponding $37 \mathrm{GHz}$ polarization differences in these regions are slightly less than the discrimination value of $10 \mathrm{~K}$. Both areas were characterized by low SWE values (less than $20 \mathrm{~mm}$ ) on the preceding day; ablation of the snowpack may have been sufficient during the 24-hour period to produce a thinner, patchy snow cover which is difficult to detect accurately with passive microwave radiometry.

\section{VALIDATION AND TESTING OF THE WET SNOW INDICATOR}

Validation and testing of the wet snow indicator has occurred during the 1990-91 and 1991-92 winter seasons with SSM/I data acquired in near real-time to support the operational Canadian prairies SWE mapping program described above. Access to the near real-time data has made the validation process both easier and more timely and accurate; the identification of wet snow areas can generally be verified by contacting the cooperating agencies who receive the SSM/I SWE maps for a report on current snow cover and temperature conditions. During winter melt events, all orbits with coverage of the prairie region can be acquired to examine daytime melt and nighttime refreeze processes. If wet snow areas, defined by the indicator during daytime orbits, exhibit SWE retrievals at night, the performance of the indicator can be verified.

One opportunity to test the performance of the wet snow indicator occurred during a late spring storm event which affected most of the Canadian Prairie region on 27 and 28 April 1991. The storm was characterized by a mixture of rain and snow, with the proportion of each varying across the area. Some areas which received predominantly snow recorded precipitation amounts as high as $80-90 \mathrm{~mm}$. SSM/I data were acquired during the course of the storm and the SWE algorithm was run to try 


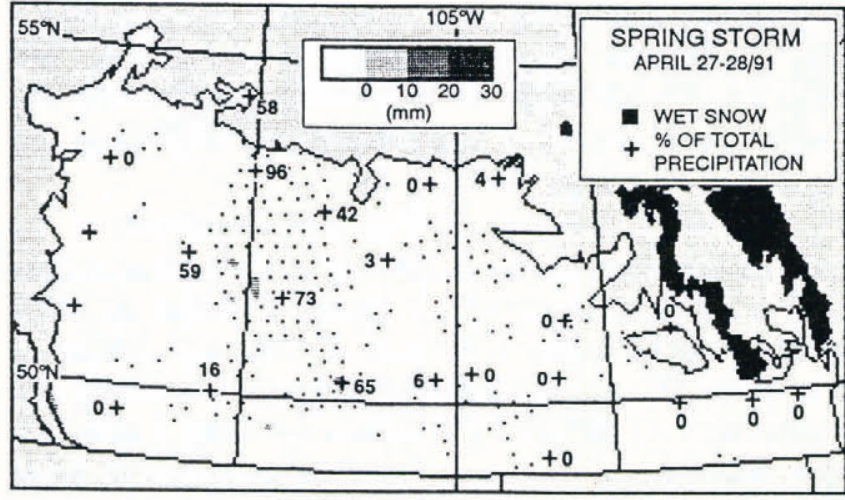

Fig. 4. SSM/I SWE for the Canadian Prairies on 29 April 1991 following a two-day spring storm event. Areas of wet snow are defined by the presence of the SSM/I wet snow indicator. Values are snowfall precipitation expressed as a percentage of total precipitation measured at synoptic stations over the storm period.

to detect the extent and amount of the resulting snow cover. Only isolated small areas of snow were detected, with SWE values being generally less than $10 \mathrm{~mm}$. Application of the wet snow indicator resulted in the identification of a much more extensive area of snow cover, as illustrated in Figure 4. Because of the combination of rain and snow during the storm, the probability was high that the snow accumulating on the ground was wet. Precipitation type and amount recorded at synoptic stations throughout the storm period provided further verification of areas where wet snow was likely. The values displayed in Figure 4 represent snowfall precipitation as a percentage of total precipitation as measured at synoptic meteorological stations over the storm period. The greatest concentration of wet snow indicators coincides with the highest percentages of snow. The regions where rain was the predominant or the only type of precipitation were generally free of the indicator.

The April 1991 spring storm illustrates the potential use of the wet snow indicator to depict snow cover conditions beyond the normal continuous winter snow cover period, when the use of current passive microwave snow algorithms may be limited due to the higher likelihood of storms producing a varying mix of rain and snow over these regions. This can also apply to snow events which occur during the fall and early winter period. The occurrence of prairie snow storms during October 1991 represented an exceptionally early start to the winter snow cover season. The application of the SSM/I SWE algorithm to orbits acquired during late October and early November of 1991 produced underestimations of both the spatial extent of the snow cover and the SWE conditions. Mixed rain and snow events were observed over the region and this is one potential cause of these underestimations; however, the effect of snow falling on warm unfrozen ground, resulting in melting at the soil/snow interface, could not be dismissed as a contributing factor. The use of the wet snow indicator in these cases improved the spatial representation of snow cover extent; for the April 1991 storm, it was the only method of identifying the spatial extent of snow on the ground with a resolution better than that provided by the synoptic station network.

Validation and testing of the SSM/I wet snow indicator is an ongoing process, which has so far been limited to the open prairie region of Western Canada where vegetation cover is minimal during the winter season. Within the boreal forest zone, which lies north of the open prairie, the use of the current wet snow indicator is limited since the $37 \mathrm{GHz}$ polarization differences are normally less than $1 \mathrm{~K}$ during winter months (Walker and Goodison, 1991). Under these conditions the polarization difference is a function of the vegetation cover present, and not the underlying snow cover conditions. During melt periods, the SSM/I SWE retrievals may drop to zero over the boreal forest region, but the wet snow indicator will generally not appear due to the $37 \mathrm{GHz}$ polarization differences falling below the threshold value of $10 \mathrm{~K}$.

\section{CONGLUSIONS}

A major limitation of current passive microwave snow water equivalent algorithms is their inability to derive quantitative snow water equivalent values when there is liquid water in or on the surface of the snowpack. In addition, they are unable to detect the presence of wet snow and hence they do not provide an accurate representation of snow extent. Although the first limitation cannot be overcome, the development of the SSM/I wet snow indicator has overcome the second limitation by providing the means to discriminate areas of wet snow from actual snow-free land in open regions and hence providing a more accurate representation of the spatial extent of snow cover during wet snow periods.

Application of the indicator to near real-time SSM/I SWE map products during the past two winters has enhanced the accuracy of the map product by indicating the presence of wet snow and providing a more representative depiction of the spatial extent of the snow cover in the prairie region. The benefits of this capability extend not only to real-time hydrological applications but also to climatological analyses of regional snow cover conditions. The indicator allows for a more accurate description of the snow cover to be derived for the shoulder seasons and for short term melt periods during the winter. The ability to identify the presence of snow on the ground under both wet and dry snowpack conditions is absolutely critical if passive microwave data are to be an effective all-weather tool for assessing snow cover variability and its link to climate change.

Although validation of the SSM/I wet snow indicator has been limited to the open prairie region of Western Canada, it may be applicable to other regions of similar terrain and vegetative characteristics. This is being tested, but validation is much more difficult since there is very limited conventional ground data for most northern regions of Canada. Research is also being conducted to derive a similar indicator for Nimbus-7 SMMR data so that a longer and more spatially accurate time series of snow cover can be derived using satellite passive microwave data. 


\section{REFERENCES}

Chang, A.T.C., J.L. Foster and D.K. Hall. 1987. Nimbus-7 SMMR derived global snow cover parameters. Ann. Glaciol., 9, 39-44.

Foster, J. L., D. K. Hall, A. T. C. Chang and A. Rango. 1984. An overview of passive microwave snow research and results. Rev. Geophys. Space Phys., 22(2), 195-208.

Goodison, B. E. 1989. Determination of areal snow water equivalent on the Canadian prairies using passive microwave satellite data. IGARSS'89. 12th Canadian Symposium on Remote Sensing. Quantitative remote sensing: an economic tool for the nineties, Vancouver, Canada, July 10-14, 1989. Volume 3, 1243-1246.

Goodison, B. E., A. E. Walker and F. W. Thirkettle. 1990. Determination of snow cover on the Canadian prairies using passive microwave data. In Proceedings of the International Symposium on Remote Sensing and Water Resources, Enschede, The Netherlands, August 1990, 127136.

Hallikainen, M. T. and P. A. Jolma. 1986. Retrieval of the water equivalent of snow cover in Finland by satellite microwave radiometry. IEEE Trans. Geosci. Remote Sensing, GE-24(6), 855-862.

Kunzi, K. F., S. Patil and H. Rott. 1982. Snow-cover parameters retrieved from Nimbus-7 Scanning Multichannel Microwave Radiometer (SMMR) data. IEEE Trans. Geosci. Remote Sensing, GE-20(4), 452-467.

Mätzler, C. 1987. Applications of the interaction of microwaves with the natural snow cover. Remote Sensing Rev., 2(2), 259-387.

Thirkettle, T., A. Walker, B. Goodison and D. Graham. 1991. Canadian prairie snow cover maps from near real-time passive microwave data: from satellite data to user information. In Proceedings of the 14th Canadian Symposium on Remote Sensing, Calgary, May 1991, 172-177.

Walker, A. E. and B. E. Goodison. 1991. Monitoring snow cover in the boreal forest region of the Canadian prairies using passive microwave satellite data. In Proceedings of the 14th Canadian Symposium on Remote Sensing, Calgary, May 1991, 296-299.

The accuracy of references in the text and in this list is the responsibility of the authors, to whom queries should be addressed. 